Эйдос, 1992. С. 332-343. URL: http://www.spbric.org/index. php?action=pub_sil_3 (дата обращения: 05.05.2020).

15. Слотердайк П. Критика цинического разума. М. ; Екатеринбург : Изд-во Урал. ун-та, 2001. 584 с.

16. Криман А. И. Идея постчеловека: сравнительный анализ трансгуманизма и постгуманизма // Философские науки. 2019. Т. 62, № 4. С. 132-147.

17. Kurzwell R. The Age of Spiritual Machines: When Computers Exceed Human Intelligence. New York ; London et al. : Penguin Books, 2000. 400 p.

18. Hassan I. Prometheus as Performer: Toward a Posthumanist Culture? // The Georgia Review. 1977. Vol. 31, № 4. P. 830-850.

19. Ferrando F. Posthumanism, Transhumanism, Antihumanism, Metahumanism, and New Materialisms: Differences and Relations // Existenz: An International Journal in Philosophy, Religion, Politics, and the Arts. 2013. Vol. 8, № 2. P. 26-32.

20. Новопашин C. А. Постчеловек VS постчеловек // Яндекс.Дзен. URL: https://zen.yandex.ru/media/id/5d

УДК 179.1

Науч. спец. 09.00.13

DOI: 10.36809/2309-9380-2020-27-14-17

\section{ЭТИЧЕСКИЕ АСПЕКТЫ АРГУМЕНТАЦИИ}

Статья посвящена рассмотрению этических аспектов аргументационной деятельности в условиях современной массовой культуры. Основной целью исследования является обоснование необходимости этической составляющей аргументации. Исследуя формы публичной аргументации, представленные современными массмедиа, автор статьи приходит к выводу о том, что проявляющееся в них отступление от этических норм не только ведет к разрушению аргументации, но и свидетельствует о моральных деформациях сознания.

Ключевые слова: аргументация, спор, эристика, общественный диалог, псевдоаргументация, легитимация морально искаженного сознания. 399a85182b5800c5fe3bb9/postchelovek-vs-postchelovek5d442aa097216d00ad698f0b (дата обращения: 05.05.2020).

21. Стругацкий А. Н., Стругацкий Б. Н. Волны гасят ветер // Знание - сила. 1985. № 6-12; 1986. № 1, 3.

22. Переслегин С. Б. «Кто хозяином здесь? Напоил бы вином...» О гипотезе люденов, или О технологии образования. 2000-2002 // Имперский Генеральный штаб : [сайт]. URL: http://www.igstab.ru/materials/black/Per_Who.htm (дата обращения: 05.05.2020).

23. Денисов А. А., Денисова Е. В. Конструирование абстрактных сознаний. Часть 1 // Информационные войны. 2013. № 1. С. 64-71.

24. Денисов А. А., Денисова Е. В. Конструирование абстрактных сознаний. Часть 2 // Информационные войны, 2013. № 4. С. 33-50.

25. Смирнов С. Дао Дзе Дун. М. : Астрель : АСТ : Полиграфиздат, 2010. 352 с.

26. Штеренберг М. И. Жизнь и время // Современная картина мира. Вып. ІІ. Формирование новой парадигмы : сб. М. : Новый век, 2001. С. 70-96.

(C) Гагарин А. С., Новопашин С. А., 2020

\section{M. Карпова \\ L. M. Karpova}

\section{ETHIC ASPECTS OF ARGUMENTATION}

The article is devoted to the ethic aspects of argumentation activity in the field of modern mass culture. The main target of the research is a support of ethic component of argumentation necessity. Researching public argumentation forms presented in modern mass media, the author of the article concludes that the derogation from the ethic standards not only leads to argumentation destruction, but also shows moral deformations of consciousness.

Keywords: argumentation, disputation, eristic, public dialogue, pseudo argumentation, legitimation of moral destructed consciousness.
Аргументация как социокультурный феномен имеет давнюю историю. Можно отнести этот вид рациональной, речевой деятельности, целью которой является доказательство и убеждение, к антропологическим и социокультурным константам. Аргументация лежит в основе всех коммуникативных процессов, носящих цивилизованный характер. Исследователи отмечают присутствие различных форм аргументационной деятельности в недрах древнейших цивилизаций как Запада, так и Востока.

Её классической формой по праву считается аргументационная культура, сложившаяся в Древней Греции в результате деятельности известных софистов и философов.
В центре этой культуры находится спор, который, будучи частным случаем аргументации, представляет её в наиболее концентрированной и острой форме. О высоком социальном статусе спора в демократическом греческом обществе свидетельствуют факты его обязательного присутствия при решении важнейших социальных проблем в сфере политики, в судебной практике, а также в области морали. Спор как вид аргументационной деятельности стал предметом особой науки, вобравшей в себя элементы искусства, - эристики. В рамках эристики разработаны методы, процедуры, рекомендации, с помощью которых было возможно достижение не только истины, но и справедливости. 
Обратим внимание на то, что изначально этическое было неотделимо от рационального, логического. Средства, предлагаемые эристикой, позволяли пропоненту (предлагающему) доказать истинность своего тезиса, убедить оппонента (возражающего) признать его.

Спор явился средством достижения истины и вместе с тем игрой. Этот фракт, очевидно, был обусловлен публичным характером, митинговой формой древнегреческой демократии. Именно необходимость не только логического, но и психологического воздействия на оппонента и публику привела к объединению эристики с риторикой, представлявшей собой искусство ораторского мастерства, благодаря которому спор обретал черты игровой деятельности, некоего театра. Аргументация в этом случае раскрывает свою эстетическую сторону, ослабляя этическое начало. Об этом свидетельствует деятельность софистов, для которых спор, нагруженный всевозможными абсурдными, парадоксальными суждениями, представал как наилучший путь победы над противником, для которой все средства хороши, утрачивая при этом своё предназначение поиска истины. И хотя многие исследователи отмечают определенную конструктивную роль деятельности софистов, состоящую в том, что в форме софизмов осознавались реальные проблемы языка и мышления, анализ которых и привел к возникновению логики как науки; все же их приемы аргументации оценивались как род интеллектуального мошенничества и осуждались. Возражая софистам, Сократ заменил софистический спор на диалектический, утвердив его истинное предназначение - поиск истины, который вернул аргументации этическую составляющую. Эту линию продолжили и развили, как известно, Платон и Аристотель. Что касается эристики, можно сказать, что она, разделившись на две части, прошла долгий исторический путь и в форме диалектики и софистики присутствует также в иных фрормах в современной культуре явно и неявно.

Подобно любому социокультурному феномену, аргументация изменяется, трансформируется, приобретает определенные специфические черты под влиянием конкретных условий культуры.

Современная массовая культура настойчиво и ярко демонстрирует такие формы публичной аргументации, которые превосходят описанные в истории состязания софистов Древней Греции по масштабу нарушений не только законов и правил логики, но и этических норм. Подобные формы аргументации особенно активно использует телевидение в различных вариантах - от рекламных роликов до демонстрации многочисленных ток-шоу, дебатов, споров по самым различным вопросам, которым подчас придается несвойственный им «общемировой» смысл.

Не отстает в этом плане и интернет: сходные «стратегии» и «тактики» ведения дискуссий и диалогов как частных случаев аргументации присутствуют и здесь, причём как явно - в интервью, рецензиях, комментариях, так и неявно - в различных заголовках субъективно-оценочного характера, сопровождающих подачу объективного новостного материала. В последнем случае без труда просматривается специфическая схема «аргументации», точнее, её деформация: в подобной подаче оппонент заявляет свою позицию раньше, чем представлена новость, т. е. позиция пропонента.

Современные массмедиа таким образом репрезентируют формы аргументации, которые на самом деле являются её профранацией, противоречат её природе, рисуя картину того, что только таким образом (унижая оппонентов, крича, ругаясь, пренебрегая всеми моральными запретами) можно и нужно что-либо доказывать и в чем-либо убеждать.

С этим тезисом, казалось бы, можно поспорить на том основании, что вряд ли подобные формы аргументации оцениваются большинством людей как серьезные, поскольку их игровой, развлекательный характер совершенно очевиден. Даже самый доверчивый и наивный зритель рано или поздно обнаруживает, что перед ним разворачивается игра, в которой есть сценарий, что ведущий выступает как актер, независимо от его профессиональной принадлежности он может действительно быть актером, или журналистом, или ещё кем-то, переквалифицировавшимся в «шоумена». От зрителя не скрывают и тот фракт, что приглашенные участники этих шоу, как правило одни и те же известные люди, уж слишком часто выступают экспертами по разным вопросам, а кроме того, другие, якобы случайные, присутствующие люди «из народа» тоже являются специально приглашенными игроками, зачастую появляющимися в других программах и на других телевизионных каналах. И наконец, зритель понимает, что представленная картина иллюзорна и не заслуживает доверия.

Действительно, казалось бы, с этим трудно не согласиться. Однако уже первый шаг критико-реслексивной процедуры исследования этого феномена позволяет обнаружить за несерьезной, развлекательной формой достаточно серьезное манипулятивное содержание. Это проявляется прежде всего в характере обсуждаемых вопросов и тем: проблемам и подробностям (порой интимного характера) частной жизни известных людей, чаще всего звезд шоу-бизнеса, придается масштаб важнейших социальных проблем, что является формой отвлечения внимания от действительных проблем, навязывания проблем мнимых.

Становится понятным, что в упомянутых формах под видом аргументации демонстрируется псевдо- и даже антиаргументация, поскольку цель действительной аргументации - убеждение, доказательство, а не манипуляция.

Следующие шаги в этом направлении позволяют обнаружить серьезную этическую проблему. Речь идет о явлении, отражающемся в понятии «инверсия морали», которое современный американский исследователь Джон Брайнт, опираясь на своих предшественников, применя ет для описания таких ситуаций, как «переворачивания», «перестановки», «превращения» истины и лжи, добра и зла, которые ведут к «легитимации морально искаженного сознания» [1, с. 65]. Автор отмечает, что «негативная мораль, или инверсия морали, включает в себя создание внешнего второго "я" со своей собственной искаженной этикой», подчеркивая, что «инверсия морали очевиднее всего проявляется в сфере корпоративных и политических программ» [1, с. 70].

Представляется, что подобные процессы происходят в рассматриваемых формах публичной аргументации, 
которые транслируют искаженную норму коммуникации, представляя её как действительную норму.

Продолжением и дополнением описания указанной тенденции является, по нашему мнению, концепт «текучее зло». Ввел его в научный оборот польско-британский политический философ и социолог Зигмунт Бауман с целью репрезентации современного, совершенно нового явления зла [2]. «Текучее зло обладает поразительным свойством - оно непревзойденно умеет маскироваться и использовать для своих нужд человеческие, слишком человеческие тревоги и желания под ложными предлогами, которые, однако, крайне трудно опровергнуть», - так описывают этот феномен 3. Бауман и его соавтор Л. Донскис [2, с. 7]. Исследователи отмечают, что «текучее зло» предстает во множестве форм, оно, подобно жидкости, проникает повсюду, «пропитав ткань повседневности» [2, с. 8].

На наш взгляд, характеристики «текучего зла» вполне приложимы к тем формам аргументации, которые способствуют распространению и легитимации агрессии в человеческих коммуникациях во внешне безобидных, развлекательных формах.

Серьезность выявленной тенденции углубляется и обостряется в процессе критического анализа такой важнейшей разновидности аргументации, как общественный диалог, транслируемый современными средствами массмедиа в фрормах политических ток-шоу, которые нацелены на выполнение функций далеко не развлекательного характера.

В этом плане представляет интерес исследование Н. В. Мотрошиловой, в котором автор, рассматривая современные формы общественного диалога, подчеркивает, что сегодня «становятся интернациональными, в высшей степени актуальными темы нарушенного, дискредитированного диалога, а также необходимости возобновления действительного диалога как одного из важнейших способов мирного выживания человечества и человеческой цивилизации» [3, с. 36]. Н. В. Мотрошилова характеризует современные общественные диалоги, например диалог народа и власти, как подмену, как имитации и профанации, причём это явление наблюдается повсеместно: «В разных странах с проявлениями демократии отождествляют как бы гласные, как бы «объективные» ток-шоу - как бы с выражением несходных, в том числе противоположных, мнений» $[4$, с. 32].

Сценарии политических ток-шоу оказываются идентичными сценариям ток-шоу развлекательного характера, отличаясь разве что большей тщательностью подготовки. Ведущие политических, так же как и развлекательных, программ специально готовятся, ими не могут быть случайные люди: их приглашают, как правило, из числа известных и достаточно авторитетных персон. Они участвуют в формировании аудитории, которая тщательно подбирается и готовится. Важно подчеркнуть, что пропоненты и оппоненты в таких формах публичной аргументации тоже, видимо, проходят тщательный отбор. Автор отмечает как характерную черту ток-шоу, представляющих диалог «власти и народа», наличие слоя «более или менее грамотных, красноречивых политиков разных рангов (в том числе депутатов - то есть самих представителей власти), но с репутацией и функциями экспертов» [4, с. 32]. Выступления этих экспертов нередко отличаются грамотностью, профессионализмом, поведение - неагрессивностью, что должно привлечь внимание образованной части зрителей. Однако не эти качества являются определяющими при их отборе. Как подчеркивает Н. В. Мотрошилова, главное требование состоит в том, что суждения выступающих «...не должны ни в коем случае выбиваться из ряда официальных, даже официозных подходов, точек зрения по обсуждаемым вопросам» [4, с. 33]. Понятно, что за соблюдением этих негласных правил следят ведущие. Подобно тому, как по сценарию развлекательных ток-шоу приглашаются люди с противоречащими позициями, сценариями политических ток-шоу предусмотрено подобное: например, в отечественные шоу приглашаются участники с антироссийскими настроениями, как отмечает автор, «их, разумеется, заслушают, но долго говорить не дадут» $[4$, c. 33]. Можно сказать, что форма политических ток-шоу представляет лишь псевдоаргументацию, демонстрируемые диалоги и споры профанируют эту важнейшую форму коммуникации. Становится понятным, что псевдодиалоги на этом уровне ведут к куда более опасным последствиям, чем просто манипулирование массовым сознанием.

Итак, рассмотренные формы публичной аргументации приводят к мысли о необходимости их замены на действительные её формы с актуализацией возврата к имеющимся в логике и теории аргументации правилам и нормам, которые органично сочетают логическое с этическим.

В качестве наиболее яркого примера подобного возврата к правилам, которые, казалось бы, давно известны, напомним положения из не менее известного, написанного более ста лет назад труда отечественного философа и логика С. Поварнина «Спор. О теории и практике спора». Этот труд, по признанию огромного числа исследователей проблем спора, содержит наиболее полное описание правил, корректных приемов и уловок спора, которые по-прежнему актуальны.

Актуален и, несомненно, современен сам поход автора работы к спору как виду аргументации, который можно охарактеризовать как междисциплинарный (хотя сам автор, естественно, так его не определяет): приемы и правила спора исследуются им не только с позиций логической теории, но и с этической и психологической.

Можно обнаружить такую интересную сторону этой работы: начиная с теоретических положений, автор незаметно подводит к практическим правилам и рекомендациям. Перед читателем выстраивается стратегия успешного ведения аргументации - спора. Абсолютно ясно, с чего следует начинать - с тезиса (ведь он, согласно образному выражению автора, «король в шахматной игре»), именно в нём выражена цель доказательства, поэтому соблюдение логических правил тезиса является необходимым условием начала аргументационной деятельности. Но тезис только первый структурный элемент аргументации, поэтому необходимо пойти дальше, последовательно разбирая правила аргументов и демонстрации, т. е. формы аргументации [5]. 
С. Поварнин констатирует необходимость знаний логики, без которых подчас не только трудно, но и невозможно обойтись: «Иногда и чувствуешь, что-то да не так, а где ошибка, определить не можешь. Вот тут-то и помогает знание логики на практике» [5].

Автор представляет целый спектр классификаций споров: «спор за мысль» и «спор за доказательство», «сосредоточенный» и «бесформенный», «простой» и «сложный», «спор без слушателей и при слушателях», «спор письменный и устный», - дополняя в этом контексте логические характеристики спора психологическими. Выделенные С. Поварниным черты спора по-прежнему актуальны. «Одной из самых трудно преодолимых преград к хорошему ведению спора является у людей неуменье слушать другого человека», — констатирует автор, отмечая, что из-за этого «многие споры обращаются в нечто невообразимо-нелепое, в какой-то ужасающий сумбур» [5].

В фокусе нашего внимания оказываются этические аспекты спора в работе С. Поварнина: говоря о «настоящем, хорошем и честном споре», он утверждает, что таковой возможен лишь тогда, когда будет «уважение к убеждениям и верованиям противника, если мы видим, что они искренни» [5]. Однако автору приходится констатировать, что это условие соблюдается редко, что являет нам «признак или некультурного и невежественного, или же узкого ума» [5] Анализируя «уловки», выступающие внелогическими приемами, содержащими элементы хитрости, применяемые с целью облегчения спора, автор обращается к тонкостям психологии спора.

Вполне осознавая, что в споре действуют живые люди со своими достоинствами и недостатками, С. Поварнин разделяет все «уловки» на позволительные (лояльные) и непозволительные (нелояльные). К числу первых он относит следующие: оттягивание возражения (чтобы выиграть время), использование «слабых мест» противника, приемы ответа на недопустимые уловки противника, способы опровержения противника его же собственным оружием.

Рассматривая непозволительные (нелояльные) приемы спора, автор подчеркивает, что наиболее грубыми из них являются те, которые он называет «механическими»: срыв спора, лишение противника возможности полноценно говорить, организация «хора» полуслушателей-полуучастников спора, «палочный аргумент», «аргумент к городовому» [5].
Кроме отмеченных выше, к нелояльным он относит те психологические приемы, целью которых является выведение противника из равновесия путем раздражения, оскорбления, обвинения его. Знание и этих приемов участникам спора, по мнению автора, необходимо для того, чтобы не только самим избегать соблазна их применять, но и быть готовыми к противостоянию им.

Посвящая отдельную главу в своей книге подробному анализу софистики, автор прозорливо отмечает, что она со временем не исчезает, а лишь приобретает новые формы.

Даже такой далеко не полный обзор основных положений концепции С. Поварнина свидетельствует о том, что труд сохраняет свою фундаментальную ценность в плане не только теории, но и практики аргументации.

В контексте этических аспектов аргументации следует подчеркнуть, что эта работа чрезвычайно ценна не только тем, что в ней содержится анализ этической стороны спора, но, что более важно, вся концепция автора свидетельствует о том, что, различаясь в теории, в практике аргументации, в частности в споре, корректность логическая не только не противоречит корректности этической, но и приближается и даже сливается с ней.

1. Брайнт Дж. Трансцендентная логика: инверсия морали // Вестн. Рос. филос. о-ва. 2004. № 2 (30). С. 62-71.

2. Бауман 3., Донскис Л. Текучее зло: жизнь в мире, где нет альтернатив / пер. с англ. А. И. Самариной ; науч. ред. М. А. Симакова. СПб. : Изд-во Ивана Лимбаха, 2019. 296 с.

3. Мотрошилова Н. В. Современные коррекции к пониманию теорий диалога и их применению в жизненном мире (опыт социологии познания). Часть I // Философрские науки. 2017. № 2. С. 34-49.

4. Мотрошилова Н. В. Современные коррекции к пониманию теорий диалога и их применению в жизненном мире (опыт социологии познания). Часть II // Философские науки. 2017. № 3. C. 23-37.

5. Поварнин С. И. Искусство спора // Библиотека Гумер культурология : [сайт]. URL:https://www.gumer.info/bibliotek Buks/Culture/Povarnin_Spor/Povarnin_index.php (дата обращения: 02.05.2020).

(C) Карпова Л. М., 2020 